\title{
ANALISIS TINGKAT KEPUASAN MAHASISWA TERHADAP KINERJA SISTEM INFORMASI AKADEMIK (SIMAK) DI PROGRAM STUDI INFORMATIKA
}

\author{
Achmad Fuad ${ }^{1}$, Endah Harisun ${ }^{2}$ \\ Program Studi Teknik Informatika, Fakultas Teknik, Universitas Khairun ${ }^{1}$ \\ Program Studi Arsitektur, Fakultas Teknik, Universitas Khairun ${ }^{2}$ \\ E-mail :ad_4ss@yahoo.com. ${ }^{1}$, endah.harisun@unkhair.ac.id ${ }^{2}$
}

\begin{abstract}
The success of academic information systems (SIMAK) is a level where information systems are able to contribute to the organization in achieving its objectives. Instead it is said to fail if the system is lacking or even not utilized by its users. In order for an information system to operate optimally, it is necessary to evaluate the information system. Because the costs incurred to implement information technology-based information systems are not small. The Informatics Engineering Program has and implements the Academic Information System (SIMAK) and supporting devices that support the implementation of academic and non-academic activities since the odd semester of the 2014/2015 academic year. This type of research is quantitative research with an analytical survey approach, which describes the situation through analysis of primary and secondary data, and data that has been collected in the form of numbers will then be calculated using the Statistical Product and Service Solution (SPSS) application, and the results of analysis data, then described descriptively to determine the extent of student satisfaction with the performance of the Academic Information System (SIMAK) in the Program Studi Informatika Universitas Kharun. While the objectives of this study are: (1). To determine the effect of system quality on student satisfaction, (2). To determine the effect of information quality on student satisfaction and (3). To determine the effect of service quality on student satisfaction. The selection of Informatics Engineering students is a research study because it uses academic information systems more often than students in other study programs within the Khairun University environment
\end{abstract}

Keyword: Academic Information System, Satisfaction, Students

Abstrak -- Kesuksesan sistem informasi akademik (SIMAK) merupakan suatu tingkat dimana sistem informasi mampu memberikan konstribusi pada organisasi dalam pencapaian tujuannya. Sebaliknya dikatakan gagal apabila sistem tersebut kurang atau bahkan tidak dimanfaatkan oleh penggunanya. Agar suatu sistem informasi dapat beroperasi secara optimal, perlu adanya evaluasi terhadap sistem informasi. Karena biaya yang dikeluarkan untuk menerapkan sistem informasi yang berbasis teknologi informasi tidak sedikit. Program Studi Teknik Informatika telah memiliki dan menerapkan Sistem Informasi Akademik (SIMAK) dan perangkat pendukung yang menunjang pelaksanaan kegiatan akademik maupun non akademik sejak semester ganjil tahun akademik 2014/2015. Jenis penelitian ini adalah penelitian kuantitatif dengan pendekatan survey analitik, yang menggambarkan keadaan melalui analisa data primer dan data sekunder, dan data yang telah terkumpul dalam bentuk angka-angka kemudian akan dihitung menggunakan aplikasi Statistical Product and Service Solution (SPSS), dan hasil dari analisa data, kemudian diuraikan secara diskripsi untuk mengetahui sejauh mana tingkat kepuasan mahasiswa terhadap kinerja Sistem Informasi Akademik (SIMAK) di Program Studi Informatika Universitas Khairun. Sedangkan tujuan dari penelitian ini adalah : (1). Untuk mengetahui pengaruh kualitas sistem terhadap kepuasan mahasiswa, (2). Untuk mengetahui pengaruh kualitas informasi terhadap kepuasan mahasiswa dan (3). Untuk mengetahui pengaruh kualitas pelayanan terhadap kepuasan mahasiswa. Pemilihan mahasiswa Program Studi Teknik Informatika sebagai studi penelitian karena lebih sering menggunakan sistem informasi akademik dibandingkan dengan mahasiswa pada program studi lain dalam lingkungan Universitas Khairun.

Kata Kunci: Kepuasan, Mahasiswa, Sistem Informasi Akademik

\section{PENDAHULUAN}

Perkembangan teknologi saat ini telah mengalami peningkatan yang sangat pesat. Perkembangan teknologi tidak hanya terjadi di satu bidang namun telah terjadi di semua segi kehidupan manusia. Salah satu teknologi yang mengalami perkembangan yang sangat pesat adalah perkembangan teknologi komputer yang telah mengalami evolusi yang sangat cepat. Dengan adanya perkembangan komputer dapat memberikan banyak keuntungan berupa ketepatan waktu, berkurangnya penanganan dokumen, dan manfaat lainnya, serta telah menjadikan informasi menjadi sangat penting.

Kepuasan pengguna merupakan salah satu bentuk evaluasi terhadap sistem informasi. Salah satu metode yang dikembangkan oleh ahli sistem informasi untuk mengukur kepuasan pengguna sistem informasi adalah dengan menilai karakteristik yang diinginkan dari sebuah sistem (kualitas sistem), karakteristik yang diinginkan dari output system 
(kualitas informasi) dan kualitas dukungan yang diterima pengguna sistem dari departemen sistem informasi dan dukungan personil informasi (kualitas pelayanan).

Pengembangan UNKHAIR diarahkan menuju research-based university dari teaching university membutuhkan perubahan yang mendasar, termasuk perubahan budaya dan etos kerja. Hal ini tentu membutuhkan dukungan kepemimpinan yang kuat dan visioner untuk menciptakan organisasi yang sehat dan iklim kerja yang kondusif bagi pengembangan dan pelaksanaan kegiatan akademik. Disisi lain, tantangan yang paling besar adalah menumbuhkembangkan budaya meneliti di kalangan sivitas akademika sebagai dasar pelaksanaan pendidikan dan pengabdian kepada masyarakat.

SIMAK dan E-learning ini merupakan hasil karya murni Program Studi Teknik Informatika. Proses perancangan, pembuatan dan implementasi SIMAK dilakukan sendiri oleh tim Program Studi Teknik Informatika yang terdiri dari 7 dosen tetap sampai selesai. Implementasi SIMAK Program Studi Teknik Informatika setahun kemudian diadopsi oleh Universitas untuk semua fakultas sampai sekarang ini.

Selain itu, Program Studi Teknik Informatika mengembangkan Software Aplikasi MABA pada tahun 2016 dan Sistem UKT (uang kuliah tunggal) pada awal tahun 2017 ini. Semua sistem informasi ini digunakan untuk menunjang proses akademik di Universitas berjalan lebih baik. (http://if.unkhair.ac.id; http://if.univ-khairun.com; http:// ukt.univkhairun.com; http://pendaftaran.univ-khairun.com).

Pemilihan mahasiswa Program Studi Teknik Informatika sebagai studi penelitian karena lebih sering menggunakan sistem informasi akademik dibandingkan dengan mahasiswa pada program studi lain dalam lingkungan Universitas Khairun. Berdasarkan penjelasan di atas maka penulis tertarik untuk menulis judul penelitian "Analisis Tingkat Kepuasan Mahasiswa Terhadap Kinerja Sistem Informasi Akademik (SIMAK) di Program Studi Informatika Universitas Khairun".

Tujuan dari penelitian ini adalah : a). Untuk mengetahui pengaruh kualitas sistem terhadap kepuasan mahasiswa, b). Untuk mengetahui pengaruh kualitas informasi terhadap kepuasan mahasiswa, c). Untuk mengetahui pengaruh kualitas pelayanan terhadap kepuasan mahasiswa dan Penelitian ini diharapkan dapat memberikan masukanmasukan yang bermanfaat bagi universitas sebagai bahan evaluasi guna mengambil kebijakan-kebijakan yang berkaitan dengan kepuasan mahasiswa.

\section{TINJAUAN PUSTAKA}

b. Aspek-Aspek Kepuasan

Aspek-aspek kepuasan konsumen Menurut pendapat Lovelock yang dikutip Tjiptono dalam Hutasoit (2011: 24), ada beberapa metode untuk mengevaluasi kepuasan, meliputi: Kinerja, Ciri-ciri tambahan, keandalan, kesesuaian spesifikasi, daya tahan, Kinerja (Performance), Karekteristik pokok dari suatu produk dan merupakan kareteristik utama yang dipertimbangkan konsumen dala membeli suatu produk. Ciri-ciri atau keistimewaan tambahan (Features), Dari fungsi dasar berkaitan dengan pilihan-pilihan produk dan pengembangannya, yaitu karakteristik skunder atau pelengkap Keandalan (Reability), Kecilnya kemungkinan suatu barang atau jasa rusak atau gagal fungsi dalam periode waktu tertentu dan kondisi tertentu Kesesuaian dengan spesifikasi (conformance to specification), Sejauh mana karekteristik desain dan operasi memenuhi standar yang ditetapkan sebelumnya berdasarkan keinginanan konsumen. Daya tahan (durability), berkaitan dengan umur teknis dan umur produk mudah diperbaiki (serviceability), meliputi kecepatan, kompetensi, kenyamanan, mudah direparasi, serta penanganan keluhan yang memuaskan Estetika (aesthetics), Daya tarik produk menurut pengindraan konsumen, misalnya model desain dan warna.

c. Faktor-Faktor Yang Mempengaruhi Kepuasan

Richard Oliver dalam Engel, dkk. (1994) telah mempelopori penelitian dengan model diskonfirmasi harapan. Konsumen melakukan pembelian dengan harapan produk sesuai apa yang diharapkannya. Para peneliti mengidentifikasi tiga jenis harapan: a) Kinerja yang wajar. Suatu penilaian normative yang mencerminkan kinerja bahwa konsumen harus menerima sesuai dengan apa yang sudah dikeluarkannya. b) Kinerja yang ideal. Tingkat kinerja ideal yang optimum atau diharapkan. c) Kinerja yang diharapkan. Bagaimana kemungkinan kinerja nantinya.

Ketiga faktor kepuasan konsumen tersebut digunakan untuk membandingkan apa yang diharapkan oleh konsumen. Kebanyakan peneliti memandang penilaian kepuasan konsumen ini sebagai penilaian subjektif mengenai perbedaan antara harapan konsumen dengan kualitas pelayanan yang diberikan.Selain itu untuk melihat bahwa konsumen juga memanfaatkan atau menikmati evaluasi kinerja atau pelayanan yang diberikan untuk konsumen.

d. Indikator Kepuasan Pengguna (Mahasiswa)

Menciptakan dan mencapai kepuasan mahasiswa sebagai pengguna suatu sistem yang diterapkan suatu perguruan tinggi, bukanlah suatu hal yang mudah bagi perusahaan tersebut, mengingat bahwa mahasiswa sebagai pengguna sistem tersebut merupakan manusia yang memiliki keinginan, harapan dan kebutuhan yang berbeda- beda, serta tidak jarang keinginan, harapan, dan kebutuhan mereka itu mengalami perubahan dari waktu kewaktu dan dalam jangka waktu yang tidak lama. Oleh karena itu suatu perusahaan atau perguruan tinggi harus senantiasa memperhatikan setiap kebutuhan dan harapan yang diinginkan oleh mahasiswanya (user) agar dapat menyajikan suatu sistem yang dapat memenuhi kebutuhan (user) dalam rangka meningkatkan kepuasan mahasiswa (user) agar dapat meningkatkan pula kinerja yang dihasilkannya. 
Kepuasan mahasiswa terhadap penggunaan SIMAK online dapat diukur dari teori yang telah disampaikan DeLone and McLean (2003) dalam The Update D\&M IS Success Model dimana ada tiga komponen yang mempengaruhi kepuasan mahasiswa, yaitu kualitas sistem, kualitas informasi, dan kualitas pelayanan. Dalam penelitian ini, peneliti hanya fokus terhadap kepuasan mahasiswa, bukan kesuksesan sistem informasi secara keseluruhan, dikarenakan keterbatasan waktu, SDM, dan biaya.

Kotler (2009:48) berpendapat bahwa "semakin tingginya tingkat kualitas pelayanan menyebabkan semakin tingginya tingkat kepuasan pelanggan", Tjiptono (2008:85) menyatakan bahwa "kualitas pelayanan yang unggul dan konsisten dapat menumbuhkan kepuasan pelanggan yang pada gilirannya akan memberikan berbagai manfaat".

\section{METODE PENELITIAN}

Jenis penelitian ini adalah penelitian kuantitatif dengan pendekatan survey analitik, yang menggambarkan keadaan melalui analisa data primer dan data sekunder, dan data yang telah terkumpul dalam bentuk angka-angka kemudian akan dihitung dan hasil dari analisa data, kemudian diuraikan secara diskripsi untuk mengetahui sejauh mana tingkat kepuasan mahasiswa terhadap kinerja Sistem Informasi Akademik (SIMAK) di Program Studi Informatika Universitas Khairun.

Dari sekian banyak cara penentuan sampel, penelitian ini menggunakan cara Non probability Sampling (Judgment Sampling). Sampel dipilih berdasarkan penilaian peneliti bahwa dia adalah pihak yang paling baik untuk dijadikan sampel penelitiannya Jadi, judgment sampling umumnya memilih sesuatu atau seseorang menjadi sampel karena mereka mempunyai "information rich". Selanjutnya Alma (2004) mengemukakan bahwa : untuk ancer-ancer apabila subjek kurang dari 100, maka lebih baik diambil semua, sehingga penelitiannya merupakan penelitian populasi. Selanjutnya jika subjeknya besar, dapat diambil diantara 10\%-15\% atau 20\%-25\% atau lebih. Maka sampel yang akan diambil adalah 619 x $10 \%=61.9$ dibulatkan menajdi 60 mahasiswa yang terdiri dari :

Tabel 1. Jumlah Sampel proporsional

$\begin{array}{ll}\text { KELOMPOK } & \text { JUMLAH } \\ \text { ANGKATAN } & \text { SAMPEL }\end{array}$

\begin{tabular}{ll}
\hline 2017 & 2 \\
& $n$ \\
2016 & 1 \\
& $n$ \\
\hline 2015 & 1 \\
& E \\
\hline
\end{tabular}

\begin{tabular}{cc}
\hline 2014 & 1 \\
& 0 \\
\hline JUMLAH TOTAL & 60 \\
\hline
\end{tabular}

IV. HASIL DAN PEMBAHASAN

A. Analisa Indeks Kepuasan Mahasiswa Terhadap Kualitas Sistem

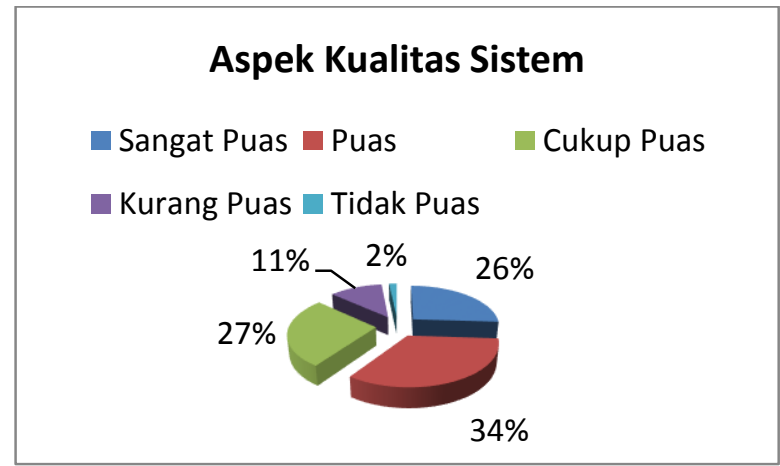

Gambar 1. Penulisan Nomor dan Judul Gambar

Berdasarkan pertanyaan tentang aspek kepuasan terhadap kualitas system SIMAK dapat dilihat bahwa dari 60 responden yang menjadi objek penelitian yang menyatakan Sangat puas sebesar $26.00 \%$, yang menyatakan puas sebesar $33.67 \%$, cukup puas sebesar $27.00 \%$, Kurang puas sebesar $11.67 \%$ dan sangat tidak puas sebesar $1.67 \%$. Hal ini menunjukan bahwa secara keseluruhan menyatakan dengan kualitas system SIMAK memiliki tingkat kepuasan yang sangat baik. Terlihat dengan nilai persentase dari pernyataan responden sebesar $33.67 \%$ yang menjawab puas. Hanya saja kalau dilihat dari gambar 1. hal yang menarik terlihat pada respon mahasiswa terhadap unsur Jaringan tidak mudah down, $35.00 \%$ menyatakan cukup puas dan $28.33 \%$ menyatakan tidak puas. Kesimpulan yang dapat ditarik adalah jaringan internet pada kawasan program studi Informatika sering down. Diharapkan kedepan agar program studi dapat mengusahakan penambahan kapasitas internet sehinnga bias stabil untuk dipergunakan oleh mahasiswa.

B. Analisa Indeks Kepuasan Mahasiswa Terhadap Kualitas Informasi

Memahami karakteristik keputusan pada tingkat manajemen maka akan menyesuaikan dengan karakteristik informasi atau laporan yang akan dibuat bagi mereka. Agustinus Mujilan (2012:30), memberikan beberapa karakteristik informasi di dalam laporan, diantaranya:a. "Kepadatan informasi, b. Luas informasi, c. Frekuensi informasi, d. Skedul informasi, e. Waktu informasi, f. Akses informasi, g. Sumber informasi".

Metode analisis yang digunakan dalam mengolah Jawaban Responden terhadap Variabel aspek kepuasan terhadap kualitas informasi SIMAK ini adalah Analisis Deskriptif Persentase. Deskriptif 
persentase ini diolah dengan cara frekuensi dibagi dengan jumlah responden dikali 100 persen.

Tanggapan responden terhadap aspek kepuasan terhadap kualitas informasi SIMAK dapat dilihat pada tabel berikut:

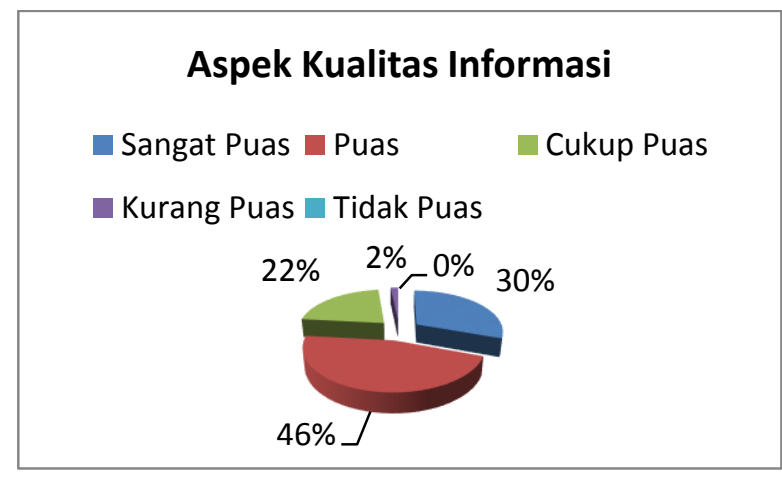

Gambar 2. hasil responden berdasarkan aspek kepuasan terhadap kualitas informasi SIMAK

Berdasarkan pertanyaan tentang aspek kepuasan terhadap kualitas Informasi SIMAK dapat dilihat bahwa dari 60 responden yang menjadi objek penelitian yang menyatakan Sangat puas sebesar $30.56 \%$, yang menyatakan puas sebesar $46.11 \%$, cukup puas sebesar $21.67 \%$, Kurang puas sebesar $1.67 \%$ dan sangat tidak puas sebesar $0 \%$. Hal ini menunjukan bahwa secara keseluruhan menyatakan dengan kualitas Informasi SIMAK memiliki tingkat kepuasan yang sangat baik. Terlihat dengan nilai persentase dari pernyataan responden sebesar $46.11 \%$ yang menjawab puas dan $30.56 \%$ menyatakan sangat puas. Hanya saja kalau dilihat dari gambar.2 hal yang menarik terlihat pada respon mahasiswa terhadap unsur Informasi disajikan sesuai kebutuhan dan sesuai dengan kegiatan sebesar $1.67 \%$. dan unsur Penyampaian informasi tepat waktu.sebesar $3.33 \%$. Kesimpulan yang dapat ditarik adalah masih ada mahasiswa yang menganggap kedua jenis pelayanan diatas belum maksimal yaitu pelayanan : a) unsur Informasi disajikan sesuai kebutuhan dan sesuai dengan kegiatan dan b) unsur Penyampaian informasi tepat waktu. Diharapkan kedepan agar program studi dapat memaksimalkan kedua pelayanan tersebut sehinnga mahasiswa sudah tidak ada lagi yang mengeluh mengenai pelayanan tersebut.

\section{Analisa Indeks Kepuasan Mahasiswa Terhadap Kualitas Pelayanan}

Berdasarkan pertanyaan tentang aspek kepuasan terhadap kualitas Pelayanan SIMAK dapat dilihat bahwa dari 60 responden yang menjadi objek penelitian yang menyatakan Sangat puas sebesar $20.38 \%$, yang menyatakan puas sebesar $47.56 \%$, cukup puas sebesar $29.23 \%$, Kurang puas sebesar
$2.56 \%$ dan sangat tidak puas sebesar $0.26 \%$. Hal ini menunjukan bahwa secara keseluruhan menyatakan dengan kualitas Pelayanan SIMAK memiliki tingkat kepuasan yang sangat baik. Terlihat dengan nilai persentase dari pernyataan responden sebesar $47.56 \%$ yang menjawab puas dan $20.38 \%$ menyatakan sangat puas.

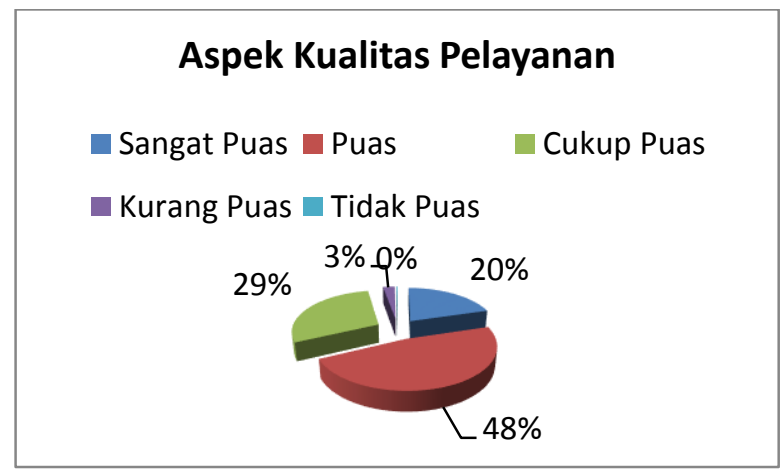

Gambar 2. hasil responden berdasarkan aspek kepuasan terhadap kualitas informasi SIMAK

Hanya saja kalau dilihat dari gambar.3 hal yang menarik terlihat pada respon mahasiswa terhadap unsur pelayanan simak ini. Ada beberapa mahaisiwa yagn merasa kurang puas terhadap terhadap kualitas pelayanan SIMAK antara lain : a) Perlengkapan fisik yang memadai sebesar $3.33 \%$ atau 2 mahasiswa, b) Penampilan Petugas SIMAK sebesar $1.67 \%$ atau 1 mahasiswa, c) Kecepatan respon petugas sebesar $1.67 \%$ atau 1 mahasiswa, d) Kesigapan petugas sebesar $1.67 \%$ atau 1 mahasiswa, e) Pelayanan via telepon.sebesar $13.33 \%$ atau 8 mahasiswa, f) Kepastian waktu.sebesar $6.67 \%$ atau 4 mahasiswa, g) Kredibilitas petugas. sebesar $1.67 \%$ atau 1 mahasiswa, h) Sikap ramah dan sopan petugas. sebesar $1.67 \%$ atau 1 mahasiswa dan i) Pemahaman terhadap permasalahan pengguna petugas. sebesar $1.67 \%$ atau 1 mahasiswa. Bahkan ada respon mahasiswa yang tidak puas terhadap kualitas pelayanan SIMAK yaitu pada pelayanan Pelayanan via telepon dan Pemahaman terhadap permasalahan pengguna.

Diharapkan kedepan agar program studi dapat memaksimalkan kualitas pelayanan simak tersebut terutama pada variable Pelayanan via telepon dan Pemahaman terhadap permasalahan pengguna sehinnga mahasiswa sudah tidak ada lagi yang mengeluh mengenai pelayanan tersebut.

\section{KESIMPULAN DAN SARAN}

\section{A. Kesimpulan}

Berdasarkan latar belakang dengan rumusan masalah mengenai kualitas system SIMAK, Kualitas Informasi 
SIMAK dan Kualitas Pelayanan SIMAK dapat ditarik kesimpulan antara lain :

- Berdasarkan pertanyaan tentang aspek kepuasan terhadap kualitas system SIMAK dapat ditarik kesimpulan bahwa kualitas system SIMAK memiliki tingkat kepuasan yang sangat baik. Terlihat dengan nilai persentase dari pernyataan responden sebesar $33.67 \%$ yang menjawab puas. Hanya saja perlu diperbaiki lagi jaringan internet pada kawasan program studi Informatika sering down dan diharapkan kedepan agar program studi dapat mengusahakan penambahan kapasitas internet sehinnga bias stabil untuk dipergunakan oleh mahasiswa.

- Berdasarkan pertanyaan tentang aspek kepuasan terhadap kualitas Informasi SIMAK dapat ditarik kesimpulan bahwa kualitas Informasi SIMAK memiliki tingkat kepuasan yang sangat baik. Terlihat dengan nilai persentase dari pernyataan responden sebesar $46.11 \%$ yang menjawab puas dan $30.56 \%$ menyatakan sangat puas. Namun masih ada mahasiswa yang menganggap kedua ada pelayanan yang belum maksimal yaitu pelayanan : a) unsur Informasi disajikan sesuai kebutuhan dan sesuai dengan kegiatan dan b) unsur Penyampaian informasi tepat waktu. Diharapkan kedepan agar program studi dapat memaksimalkan kedua pelayanan tersebut sehinnga mahasiswa sudah tidak ada lagi yang mengeluh mengenai pelayanan tersebut.

- Berdasarkan pertanyaan tentang aspek kepuasan terhadap kualitas Pelayanan SIMAK dapat ditarik kesimpulan bahwa kualitas Pelayanan SIMAK memiliki tingkat kepuasan yang sangat baik. Terlihat dengan nilai persentase dari pernyataan responden sebesar $47.56 \%$ yang menjawab puas dan $20.38 \%$ menyatakan sangat puas. Diharapkan kedepan agar program studi dapat memaksimalkan kualitas pelayanan simak tersebut terutama pada variable Pelayanan via telepon dan Pemahaman terhadap permasalahan pengguna sehinnga mahasiswa sudah tidak ada lagi yang mengeluh mengenai pelayanan tersebut.

B. Saran

Disarankan kepada pihak universitas agar lebih meningkatkan layanan SIMAK Universitas Khairun guna terselenggaranya Tri Dharma Perguruan tinggi yang semakin baik dan berbasis Internet.

\section{DAFTAR PUSTAKA}

1) Arikunto, S. 2006. Prosedur Penelitian Suatu Pendekatan Praktek. Jakarta: Rineka Cipta
2) DeLone, W.H and McLean, E.R. (2003). The DeLone and McLean Model of Sistem Success: A Ten-Year Update, Journal of Mangement Information Sistem, 19 (4), 9-30.

3) Dwi Priyatno. 2008. Mandiri Belajar SPSS (Stastistical Product and Service Solution) untuk Analisis Data dan Uji Statistik. Yogyakarta: Mediakom. FandyTjiptono. 2002. Manajemen Jasa. Yogyakarta: Andi Offset.

4) Fakultas Keguruan dan Ilmu Pendidikan Universitas Sebelas Maret. (2012).Pedoman Penulisan Skripsi.

5) Ghozali,imam. (2005). Model Persamaan Struktural. Semarang :Badan PenerbitUniversitas Diponegoro.

6) Hair, J.F., Anderson, R. E., Tatham, R. L., and Black, W. C., (1995). Multivariate Data Analysis, Fourth Edition, New Jersey: Prentice Hall.

7) Husaini Usman, dan Purnomo SetiadiAkbar. 2004. Metodologi Penelitian Sosial. Jakarta : Bumi Aksara.

8) Husein Umar. 2003. Metode Riset: Perilaku Konsumen Jasa, Bogor: Ghalia Indonesia.

9) J. Supranto. 2006. Pengukuran Tingkat Kepuasan Pelanggan Untuk Menaikkan Pangsa Pasar. Jakarta: Rineka Cipta.

10) Jogiyanto, HM. 2007. Model Kesuksesan Sistem Teknologi Informasi. Yogyakarta: Andi.

11) Lies Sudibyo. 2011. Peranan dan Dampak Teknologi Informasi dalam Dunia Pendidikan di Indonesia. Jurnal Widyatama No.2 / Volume 20 / 2011.

12) Purbayu Budi Santosa dan Ashari. 2005. Analisis Statistik dengan Microsoft Excel dan SPSS. Yogyakarta : Penerbit Andi.

13) Sugiyono. 2009. Metode Penelitian Kuantitatif, Kualitatif dan R\&D. Bandung: Alfabeta.

14) Tjiptono, Fandy. 2004. Prinsip-prinsip total quality service, Edisi 2, Cetakan 1, Yogyakarta: Andi.

15) Zeithaml, Valerie A., and Bitner, Marie Jo. (1996). Services Marketing. McGrawill: New York.

16) Zulian Yamit. 2005. Manajemen Kualitas Produk \& Jasa. Yogyakarta: Ekonisia. 